\title{
REVISÃO ÉTICA NA PESQUISA EM CIÊNCIAS HUMANAS E SOCIAIS
}

\begin{abstract}
A ciência moderna se autoproclamou, soberbamente, a mais exata e proveitosa estratégia humana de alcançar a verdade absoluta, universal 1 e definitiva. Neste processo, ao mesmo tempo em que se liberta dos to fundado no sujeito dito cartesiano. Este novo paradigma científico inscreve a relação entre conhecimento e poder na ordem do privado, definindo este espaço como o ambiente estratégico de libertação do humano. Ao consagrar seus pressupostos metodológicos como inquestionáveis, a ciência se torna, ela mesma, um novo absoluto a dominar o homem. A subjetividade, a criticidade e a autonomia se submetem à suposta descoberta definitiva do pensamento científico.
\end{abstract}

O grande desafio que este quadro coloca é o de encontrar um novo ponto de referência que garanta, de algum modo, a possibilidade de se avaliar criticamente o desenvolvimento e os rumos do conhecimento e da ciência contemporâneos, tendo em vista suas implicaçóes cada vez mais preocupantes para a vida planetária e humana. O único caminho possível parece ser o de vincular os interesses setoriais da ciência e tecnologia aos interesses e direitos comuns relacionados ao equilíbrio natural e ao bem-estar do homem e da humanidade.

De fato, a expressão 'ciência e ética' designa esta preocupação frente aos problemas éticos enfrentados por pesquisadores em suas atividades relacionadas à instituição ciência consagrada à produção do conhecimento universal, objetivo, neutro e, pretensamente, sem fronteiras. Embasados em ampla tradição da neutralidade axiológica da ciência, assumem a tese de que não se pode extrair consequências morais de enunciados científicos. Neste sentido, a ciência náo teria que se importar com exigências provenientes das esferas política, religiosa ou socioambiental. Ademais, seria tarefa de cada cientista evitar a interferência de convicçóes éticas pessoais nas suas atividades investigativas, sob pena de incorrer em grosseira e comprometedora violação da neutralidade científica.

O ponto em questão é se o pesquisador deve ou não prestar contas aos seus iguais e à sociedade a respeito do sentido e das implicaçôes de suas atividades. Diante da crescente capacidade de intervenção da ciência, a tese da neutralidade 
torna-se cada vez mais insustentável visto que, de um lado, os resultados das investigações abrangem esferas nucleares da ética e, de outro, se constata o comprometimento de certos cientistas com algumas das mais detestáveis ideologias do século XX. Imre Lakatos e Thomas Kuhn mostram que mesmo os núcleos mais duros, tidos como objetivos e infalsificáveis, são claramente tributários de pressupostos, interesses e valores externos a eles.

Em resumo, hoje se póe sob suspeita a neutralidade racional científica cujo caráter não é necessariamente benéfico ao ser humano, à sociedade ou ao ambiente. Nestes termos, a ética do pesquisador não se limita à prática da boa ciência, supondo que o resto se dê por natural acréscimo. A história da ciência desde o século XVII até hoje pode ser dividida, grosso modo, em três fases, a saber: ciência dos aficionados, ciência acadêmica e ciência industrial. $\mathrm{Na}$ universidade atual, em boa medida comprometida com os princípios utilitaristas e mercadológicos da atualidade, os três momentos existem coetaneamente. Ainda que algumas áreas, tais como a matemática pura ou a física teórica, as questóes éticas não sejam tão relevantes, no campo das ciências da vida - onde os procedimentos são inseparáveis da experimentação com animais e seres humanos -, as questôes éticas se tornam tanto mais relevantes.

Por esta razão, foram criados e vêm se ampliando, de forma exponencial a partir de meados dos anos 1990, os Comitês de Ética em Pesquisa com Seres Humanos, tendo como marco referencial a Resolução n. 196/96, do Conselho Nacional de Saúde. Essa Resolução imprime um caráter de obrigatoriedade a existência de Comitês de Ética, no ambiente acadêmico, ao definir que: "[...] cada área temática de investigação e cada modalidade de pesquisa, além de respeitar os princípios emanados deste texto, deve cumprir com as exigências setoriais e regulamentaçóes específicas”. (BRASIL, 1996)

Embora a referida Resolução regulamentasse a revisão das implicações éticas em todas as áreas do conhecimento, seu escopo, assim como as seções "riscos e benefícios" e "protocolo de pesquisa" foram pautados em parâmetros da área de Ciências Médicas. Ademais, o próprio fato de a Comissão Nacional de Ética em Pesquisa (Conep) estar vinculada ao Conselho Nacional de Saúde do Ministério da Saúde é emblemática em sua relação orgânica com a área de saúde:

VIII - COMISSÃO NACIONAL DE ÉTICA EM PESQUISA (CONEP/MS)

A Comissão Nacional de Ética em Pesquisa - CONEP/MS é uma instância colegiada, de natureza consultiva, deliberativa, normativa, independente, vinculada ao Conselho Nacional de Saúde.(BRASIL, 1996) [Grifos nossos] 
Em 2012, o Conselho Nacional de Saúde do Ministério da Saúde, revisou e atualizou a Resolução n. 196/96, ao publicar a Resolução n. 466 de 12 de dezembro de 2012 (BRASIL, 2012), que se constitui no atual documento-referência para a organização da dinâmica de funcionamento dos Comitês de Ética em Pesquisa em Seres Humanos. Tais comitês, por sua vez, têm como propósito fazer a gestão dos protocolos de pesquisa e dos procedimentos de regulamentação da revisão ética na pesquisa com seres humanos no meio acadêmico.

Sendo tema relativamente novo no campo acadêmico, ainda são comuns dúvidas concernentes ao papel, estrutura e funcionamento do comitê de ética na pesquisa, assim como são recorrentes imprecisóes relacionadas à utilização de terminologias neste processo. Neste sentido, Carvalho e Machado (2014), ressaltam a importância em diferenciar duas expressóes que, nos últimos anos, têm pautado nossas preocupaçóes acadêmicas sobre o cuidado e a responsabilidade na produção do conhecimento: "ética" e "integridade" na pesquisa. Embora sendo de dimensóes correlacionadas, que tratam dos fundamentos morais da prática científica e definem boas práticas, os autores sustentam que pertencem a duas esferas diferentes.

\begin{abstract}
A integridade na Pesquisa diz respeito à conduta do pesquisador no tratamento dos dados e na publicação da pesquisa. É nesta esfera que se definem as orientaçóes e normas que buscam evitar fraudes tais como o plágio, o autoplágio, a fabricaçáo e/ou segmentaçáo de dados, autoria indevida. Embora estes aspectos denominados de integridade na pesquisa digam respeito ao campo da ética, como horizonte norteador da conduta moral desejável do pesquisador científico, o que se convencionou chamar de Ética na Pesquisa abrange especificamente os procedimentos de proteção aos participantes de pesquisa diante dos riscos das pesquisas envolvendo seres humanos. (CARVALHO; MACHADO, 2014, p. 2011)
\end{abstract}

Com efeito, essa segunda dimensão - integridade - é objeto das duas resoluçôes em discussão aqui. Vale ressaltar que, embora os efeitos das mencionadas Resoluçóes sejam relativamente recentes, no campo acadêmico brasileiro, a preocupação com a ética na pesquisa remonta ao período após a Segunda Guerra Mundial, sendo um de seus marcos referenciais o Código de Nüremberg, o primeiro documento a enfatizar a necessidade do consentimento do indivíduo pesquisado ${ }^{1}$. Assim, historicamente, tem-se criado consensos em torno da necessidade de estabelecer normas que regulamentem a relação pesquisador/pesquisado mediante procedimentos que possam causar constrangimentos ou mesmo ferir, direta ou indiretamente, a dignidade de pessoas ou comunidades investigadas. 
Embora tenhamos convicção de que a "ética precisa estar no pesquisador", os processos regulatórios para referenciar pesquisas que envolvem seres humanos, a exemplo da Resolução n. 466/12 e da criação de comitês locais de ética na pesquisa, são medidas importantes para propiciar a mediação de acordos entre o pesquisador e o pesquisado, selando compromissos e reforçando o resguardo dos direitos dos participantes de pesquisas. Segundo o Conselho Nacional de Saúde,

O Comitê de Ética em Pesquisa (CEP) é um colegiado interdisciplinar e independente [...], que deve existir nas instituiçóes que realizam pesquisas envolvendo seres humanos no Brasil, criado para defender os interesses dos sujeitos da pesquisa em sua integridade e dignidade e para contribuir no desenvolvimento da pesquisa dentro de padróes éticos. [...] A missão do CEP é salvaguardar os direitos e a dignidade dos sujeitos da pesquisa. Além disso, O CEP contribui para a qualidade das pesquisas e para a discussão do papel da pesquisa no desenvolvimento institucional e no desenvolvimento social da comunidade. Contribui ainda para a valorização do pesquisador que recebe o reconhecimento de que sua proposta é eticamente adequada. [...] O CEP, ao emitir parecer independente e consistente, contribui ainda para o processo educativo dos pesquisadores, da instituição e dos próprios membros do comitê. [...] Finalmente, o CEP exerce papel consultivo e, em especial, papel educativo para assegurar a formação continuada dos pesquisadores da instituição e promover a discussão dos aspectos éticos das pesquisas em serres humanos na comunidade. Dessa forma, deve promover atividades, tais como seminários, palestras, jornadas, cursos e estudos de protocolos de pesquisa. (TOMANIK, 2008, p. 396)

Assim, considerando situaçóes de negligência com seres humanos durante a realização de pesquisas, a comunidade científica tem reconhecido a expressiva pertinência da atuação dos Comitês de Ética em Pesquisa (CEP), bem como a legitimidade das Diretrizes e Normas Regulamentadoras de Pesquisas em Seres Humanos instituídas pela Resolução n. 196/1996 (BRASIL, 1996) e reformulada pela Resolução n. 466/2012 (BRASIL, 2012). No entanto, quando se trata da área de Ciências Humanas e Sociais, o quadro é bastante controverso e guarda muitos dissensos e descontentamentos em torno das referidas normas regulamentadoras devido as incompatibilidades na transposição do modelo da área de Ciências Médicas para a área de Ciências Humanas e Sociais.

Com efeito, de acordo com informações colhidas no sítio da Associação Brasileira de Pesquisa e Pós-Graduação em Educação (Anped), diferentes entidades acadêmicas da área de Ciências Humanas e Sociais "[...] têm apresentado um posicionamento de oposição à forma pelas quais os projetos de pesquisas dessas áreas têm sido examinados pelo Sistema da Comissão Nacional de Ética em 
Pesquisa (Conep), criado pela Resolução no 196/1996, do Conselho Nacional de Saúde, do Ministério da Saúde”.

Ainda de acordo com informações da Anped, a Associação Brasileira de Antropologia (ABA) foi uma das associaçóes que apresentou, em 2011, a proposta de que a Resolução n. 196/1996 ficasse restrita às pesquisas biomédicas, dizendo-se, inclusive, disposta a elaborar uma regulamentaçáo específica, fora da área da Saúde. Assim,

[...] a partir da articulação das Associaçóes e Sociedades Científicas da área de Ciências Humanas, em agosto de 2013, na sede da Conep em Brasília, foi realizada a primeira reunião de um GT visando a elaboração de uma resolução complementar à Resolução n. 466/12, referente à pesquisa nas áreas de Ciências Humanas e Sociais.

Além da proposição de resolução complementar específica para a área de Ciências Humanas e Sociais, têm sido também recorrentes as manifestaçôes em prol da desvinculação da regulação da pesquisa em Ciências Humanas e Sociais do Ministério da Saúde e sua migração para o Ministério da Ciência, Tecnologia e Inovação (MCTI). Conforme informaçóes do portal da Anped, no mês de outubro de 2014, o GT de Ciências Humanas e Sociais da Conep, concluiu a proposta de resolução específica de ética em pesquisa em Ciências Humanas e Sociais. No entanto, a Conep recusou, em 28 de janeiro de 2015, a referida proposta que deveria complementar a Resolução 466/2012. Fonseca (2015), ao recuperar os argumentos do Conep - por ocasião da recusa - expostos em uma carta pública lembra que a referida entidade repudia a ideia de que "[...] a pesquisa com seres humanos possa ter 'valores e pesos diferentes, dependendo da metodologia empregada' e insiste numa regulação única para todas as áreas [...].” (p. 361). Contrapondo-se a tal perspectiva, a autora afirma que "[...] na discussão dos tratados nacionais e internacionais surgidos para proteger 'populaçóes vulneráveis' contra os avanços do mercado farmacêutico, torna-se evidente o quanto as regulaçóes variam no espaço e no tempo" e questiona "[...] como saber onde encontrar 'critérios únicos e uniformes, independentemente da área de conhecimento?'”. (FONECA, 2015) Destarte, vale ressaltar que os tratados e consensos em torno dos códigos de ética na pesquisa são derivaçôes de lutas, tensôes e produções históricas ensejadas em determinados contextos e sob determinados axiomas das ciências, portanto, a regulação universal, atemporal e a-histórica torna-se tergiversação sem sustentação consistente.

Ainda de acordo com Fonseca (2015), a carta Conep pretende lembrar aos membros do GT-CHS que "não é possível promover a ruptura entre a análise ética e científica”, visando justificar a extensão da autoridade dos CEPs não só para 
os aspectos éticos das pesquisas na área das humanas, mas também para o próprio fundo teórico-metodológico dessas pesquisas. Sem embargo, tal argumento ancora-se na falta de reconhecimento da pluralidade e singularidade de procedimentos metodológicos dos diferentes campos epistêmicos, negando idiossincrasias dos estatutos epistemológicos das múltiplas áreas do conhecimento e de seus processos de materialização no campo empírico durante a realização das pesquisas.

Depreende-se daí que é relevante considerar os argumentos de diferentes entidades acadêmicas e sociedades científicas da área de Ciências Humanas e Sociais que têm envidado esforços, no âmbito do Conselho Nacional de Saúde, visando a conquista de autonomia no desenvolvimento de pesquisas e de definição do risco aos sujeitos participantes, dadas as idiossincrasias de matrizes teóricas, estatutos epistemológicos e procedimentos metodológicos de áreas do conhecimento, que não desencadeiem maleficências nos sujeitos pesquisados.

Consideramos legítimas as preocupações com a preservação dos direitos humanos, bem como a necessidade de defesa da dignidade humana e proposiçóes visando a proteção do ser humano (colaborador de pesquisas em andamento) de maleficências, preconizados pelas resoluções do Conselho Nacional de Saúde e implementadas, historicamente, pelos comitês locais de ética na pesquisa. As divergências concernem tão somente às transposiçóes lineares e unilaterais das metodologias de avaliação e controle próprias da área de Ciências Médicas para a área de Ciências Humanas e Sociais, dificultando a fluência dos processos e a exequibilidade dos projetos de pesquisa em função da subsunção de uma área em outra. O reconhecimento das singularidades da área de Ciências Humanas e Sociais não está ancorado em posiçóes de disputas de poder no campo epistêmico, tampouco, se encontra pautado em concepçóes corporativistas e competitivas entre áreas do conhecimento, mas referencia-se no reconhecimento das singularidades que conferem identidades próprias às metodologias dos campos de conhecimento que compóe a área de Ciências Humanas, Sociais e Sociais Aplicadas.

\section{Notas}

1. O próprio preâmbulo da Resolução n. 196/96 remonta aos documentos que referenciaram sua elaboração. "A presente Resolução fundamenta-se nos principais documentos internacionais que emanaram declaraçóes e diretrizes sobre pesquisas que envolvem seres humanos: o Código de $\mathrm{Nu}$ remberg (1947), a Declaração dos Direitos do Homem (1948), a Declaraçáo de Helsinque (1964 e suas versóes posteriores de 1975, 1983 e 1989), o Acordo Internacional sobre Direitos Civis e Políticos (ONU, 1966, aprovado pelo Congresso Nacional Brasileiro em 1992), as Propostas de Diretrizes Éticas Internacionais para Pesquisas Biomédicas Envolvendo Seres Humanos (CIOMS/ OMS 1982 e 1993) e as Diretrizes Internacionais para Revisão Ética de Estudos Epidemiológicos (CIOMS, 1991). Cumpre as disposiçōes da Constituição da República Federativa do Brasil de 1988 e da Legislação brasileira correlata: Código de Direitos do Consumidor, Código Civil e Código Penal, Estatuto da Criança e do Adolescente, Lei Orgânica da Saúde 8.080, de 19/09/90 (dispóe sobre as condiçóes de atenção à saúde, a organização e o funcionamento dos serviços correspondentes), Lei 8.142, de 28/12/90 (participação da comunidade na gestão do Sistema Único de Saúde), Decreto 99.438, de 07/08/90 (organização e atribuiçóes do Conselho Nacional de Saúde), Decreto 
98.830, de 15/01/90 (coleta por estrangeiros de dados e materiais científicos no Brasil), Lei 8.489, de 18/11/92, e Decreto 879, de 22/07/93 (dispóem sobre retirada de tecidos, órgãos e outras partes do corpo humano com fins humanitários e científicos), Lei 8.501, de 30/11/92 (utilização de cadáver), Lei 8.974, de 05/01/95 (uso das técnicas de engenharia genética e liberação no meio ambiente de organismos geneticamente modificados), Lei 9.279, de 14/05/96 (regula direitos e obrigaçóes relativos à propriedade industrial), e outras".

\section{Referências}

BRASIL. Ministério da Saúde. Conselho Nacional de Saúde. Resolução n. 196, de 10 de outubro de 1996. Aprova as diretrizes e normas regulamentadoras de pesquisas envolvendo seres humanos. Brasília, Diário Oficial da União, 16 out. 1996.

Ministério da Saúde. Conselho Nacional de Saúde. Resolução n. 466, de 12 de dezembro de 2012. Aprova diretrizes e normas regulamentadoras de pesquisas envolvendo seres humanos. Brasília, Diário Oficial da Uniáo, 12 dez. 2012.

CORONATO, M. Cobaias Humanas. Revista Superinteressante. São Paulo: Editora Abril, ed. 198, mar. 2004. Disponível em: <http://super.abril.com.br/ciencia/cobaias-humanas $>$. Acesso em 13 de junho de 2015.

FONSECA, C. Situando os comitês de ética em pesquisa: o sistema CEP (Brasil) em perspectiva. Horizontes Antropológicos, Porto Alegre, ano 21, n. 44, p. 333-369, jul./dez. 2015.

GUERRIERO, I. C. Z.; MINAYO, M. C. de S. O desafio de revisar aspectos éticos das pesquisas em ciências sociais e humanas: a necessidade de diretrizes específicas. Physis Revista de Saúde Coletiva, Rio de Janeiro, v. 23, n. 3, p. 763-782, 2013. Disponível em: <http://ref.scielo.org/dkpg87>. Acesso em 10 de junho de 2015.

LA FARE, M. de; MACHADO, F. V.; CARVALHO, I. C.de M. Breve revisão sobre regulação da ética em pesquisa: subsídios para pensar a pesquisa em educação no Brasil. Práxis Educativa, Ponta Grossa, v. 9, n. 1, p. 247-283, jan./jun., 2014. Disponível em: <http:// www.revistas2.uepg.br/index.php/praxiseducativa $>$. Acesso em 11 de junho de 2015.

TOMANIK, E. A. A ética e os comitês de ética em pesquisa com seres humanos. Psicologia em Estudo, Maringá, v. 13, n. 2, p. 395-404, abr./jun. 2008. Disponível em: <http://ref. scielo.org/bzgm7h $>$. Acesso em 12 de junho de 2015.

SEVERINO, A. J. Dimensão ética da investigação científica. Práxis Educativa, Ponta Grossa, v. 9, n. 1, p. 199-208, jan./jun., 2014. Disponível em: <http://www.revistas2. uepg.br/index.php/praxiseducativa $>$. Acesso em 09 de junho de 2015.

DOI: http://dx.doi.org/10.1590/ES0101-73302015v36n133ED 